\title{
EDITORIAL
}

\section{Respiratory effects of diving}

\author{
J.E. Cotes*
}

The illnesses caused by commercial diving were formerly mainly the province of neurologists, orthopaedic surgeons and specialist accident services. They are now also of concern to chest physicians. This editorial explains why, and highlights important new research from Norway, published in this issue of The Journal [1], which indicates ways of preventing what might still be a cause of chronic respiratory disease.

Commercial deep sea diving offers adventure and high wages, but little job security. Divers are usually employed by diving support companies, that have made huge investments in sophisticated equipment. The companies now mainly engage experienced men, and use them intensively, so that fewer jobs are becoming available. Many divers are more than 40 yrs old, and yet are reluctant to change to less arduous occupations. Thus, the divers and the companies share an interest in adopting work schedules which maximize the short-term profit. The schedules might give rise to chronic ill health, but this possibility has been of less concern than that the dives are not complicated by acute illnesses. Acute complications can include atelectasis due to an obstructed airway, barotrauma from expansion of gas present somewhere in the respiratory tract, and "bends" or "chokes" from bubbles of nitrogen which can form in the tissues or blood stream during decompression. In the longer term, bubbles can cause avascular necrosis of some bones; they may also cause degenerative changes in the brain, spinal cord and retina [2], but the possible association with diving has not been confirmed by controlled studies.

The lungs can be affected in other ways. Amongst divers attending for their routine medical examination, there is a positive association between diving exposure and the annual change in forced vital capacity [3], and a negative association between diving exposure and the annual change in forced expiratory flow at a small lung volume [4]. The increase in lung size is usually attributed to training of the respiratory muscles by increased airway and extrathoracic resistance's during the dives. The changes are reversible, and their main clinical relevance is as possible obstacles to the diagnosis of other respiratory conditions. The aetiology and clinical significance of what appears to be small airway disease is unknown.

Saturation dives to depths in excess of $50 \mathrm{~m}$ can entail equilibration of body tissues with gas mixtures containing helium, oxygen, nitrogen, hydrogen or other

* Respiration and Exercise Laboratory, Dept. Physiological Sciences, Medical School, Newcastle-upon-Tyne, NE2 4HH, UK. gases at high pressure. The pressure is applied progressively, over a period of hours or days, in a compression chamber, and then maintained. Whilst at pressure, the men are transferred to a diving bell or capsule for operational work. Depending on the equilibration pressure, the subsequent return to sea level conditions can take up to 18 days; this is expensive in time and equipment. The time for degasification is a function of the solubility of the gas [5] and the tissue-to-alveolar partial pressure gradient. The time can be minimized: 1) by adopting a high rate of decompression, which also increases the rate of tissue bubble formation; 2) by raising the inspired oxygen partial pressure, but at the risk of oxygen toxicity; or 3) by increasing the tissue blood flow. The last is, at present, only of theoretical interest. The other two are ingredients of most decompression schedules. Evidence for the schedules possibly being unsatisfactory came from the finding that saturation dives which did not give rise to accepted signs of oxygen toxicity were associated both with the changes in lung volumes and flow rates mentioned earlier and with reductions in maximal oxygen uptake [6] and transfer factor [7-9]. The latter changes were larger than could have been due to a reduced haemoglobin concentration consequent on hyperoxia. Subsequently, the transfer factor increases somewhat, but on average was not restored to the level found in control divers [10].

Studies of the likely mechanisms for these changes need to overcome the difficulty that exposures to hyperbaria, hyperoxia and pulmonary intravascular bubbles have different time profiles, and yet are to some extent intercorrelated. In addition, the measurement of the bubble load on the lung is technically difficult, there is only partial agreement on what are the appropriate indices of exposure, and few saturation dives have been documented adequately. Thus, the respective contributions of the different factors to the overall changes cannot be easily separated.

THORSEN et al. [1] have made a big advance, through two experimental dives, one to 1.5 atmospheres absolute (ATA) breathing air and the other to 2.5 ATA with a conventional pressure profile but a hyperoxic profile which matched that of a deep saturation dive. Neither dive was associated with material hyperbaric or bubble scores, so that the effects on the lungs were mainly due to hyperoxia. The results of these and some commercial test dives are reported [1]. The findings are not definitive, since no allowance could be made for any silent bubbles that occurred during decompression. In addition, some of the men had participated in more than one of the documented 
dives, and all of them had also performed other dives. Hence, there is no certainty that the narrowing of small airways in uniquely due to hyperoxia, or the increased residual and closing volumes to hyperbaria; however, that the prevailing levels of hyperoxia caused acute and sub-acute changes in the lung parenchyma is now beyond doubt. On this account, adult respiratory distress syndrome might provide a model for the possible longterm sequelae [11]. Of greater importance, the way is now open for prevention.

\section{References}

1. Thorsen E, Segadal K, Kambestad BK. - Mechanisms for reduced pulmonary function after a saturation dive. Eur Respir J 1994; 4: 4-10.

2. Bennett PB, Elliott DH, Eds. - In: The Physiology and Medicine of Diving. 4th edn. London, WB Saunders, 1993.

3. Davey IS, Cotes JE, Reed JW. - Relationship of ventilatory capacity to hyperbaric exposure in divers. $J$ Appl Physiol: Respirat Environ Exercise Physiol 1984; 56: 1655-1658.

4. Elliott C, Reed JW, Cotes JE, Robinson NG, King J. -
Narrowing of small lung airways in commercial divers. In: Sterk W, Geeraedts L, eds. Proc XVIth EUBS Conference 1990; pp. 197-202.

5. Ketty SS. - The theory and application of the exchange of inert gas at the lungs and tissues. Pharm Rev 1951; 3: $1-41$.

6. Thorsen E, Hjelle J, Segadal K, Gulsvik A. - Exercise tolerance and pulmonary gas exchange after deep saturation dives. J Appl Physiol 1990; 68: 1809-1814.

7. Cotes JE, Davey IS, Reed JW, Rooks M. - Respiratory effects of a single saturation dive to $300 \mathrm{~m}$. Br J Ind Med 1987; 44: 76-82.

8. Thorsen E, Segadal K, Myrseth E, Påsche A, Gulsvik A. - Pulmonary mechanical function and diffusion capacity after deep saturation dives. Br J Ind Med 1990; 47: 242247.

9. Dujić Z̆, Eterović D, Denoble P, Krstačić G, Tocilj J, Gošović S. - Effect of a single air dive on pulmonary diffusing capacity in professional divers. $J$ Appl Physiol 1993; 74: 55-61.

10. Thorsen E, Segadal K, Kambestad B, Gulsvik A. Divers' lung function: small airways disease? $\mathrm{Br} J$ Ind Med 1990; 47: 519-523.

11. Murray JF, Matthay MA, Luce JM, Flick MR. - An expanded definition of the adult respiratory distress syndrome. Am Rev Respir Dis 1988; 138: 720-723. 